2013-04-01

\title{
Protein Kinase C Delta is a Substrate of Tissue Transglutaminase and a Novel Autoantigen in Coeliac Disease
}

\author{
Greg Byrne \\ Technological University Dublin, greg.byrne@tudublin.ie \\ Michael Freeley \\ Trinity College Dublin \\ Con Feighery \\ Trinity College Dublin
}

See next page for additional authors

Follow this and additional works at: https://arrow.tudublin.ie/scschbioart

Part of the Immunopathology Commons

\section{Recommended Citation}

Byrne, G. M., Freeley, M., Feighery, C., Whelan, A., Long, A., (2013) "Protein Kinase C Delta is a Substrate of Tissue Transglutaminase and a Novel Autoantigen in Coeliac Disease", Clinical Immunology, Volume 147, Issue 1, April 2013, Pages 1-8, ISSN 1521-6616, doi:10.1016/j.clim.2013.01.007

This Article is brought to you for free and open access by the School of Biological Sciences at ARROW@TU Dublin. It has been accepted for inclusion in Articles by an authorized administrator of ARROW@TU Dublin. For more information, please contact arrow.admin@tudublin.ie, aisling.coyne@tudublin.ie,gerard.connolly@tudublin.ie.

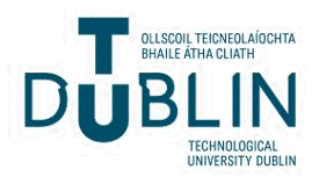


Authors

Greg Byrne, Michael Freeley, Con Feighery, Alex Whelan, and Aideen Long

This article is available at ARROW@TU Dublin: https://arrow.tudublin.ie/scschbioart/83 


\title{
Protein kinase C delta is a substrate of tissue transglutaminase and a novel autoantigen in coeliac disease
}

\author{
Greg Byrne $^{a, *}$, Michael Freeley ${ }^{b}$, Con Feighery ${ }^{c}$, \\ Alex Whelan ${ }^{c}$, Aideen Long ${ }^{b}$
}

\author{
a School of Biological Sciences, Dublin Institute of Technology, Dublin 8, Ireland \\ b Department of Clinical Medicine, Institute of Molecular Medicine, Trinity College Dublin, Dublin 8, Ireland \\ c Department of Immunology, St. James's Hospital \& Trinity College Dublin, Dublin, Ireland
}

Received 5 November 2012; accepted with revision 17 January 2013

\section{KEYWORDS}

Coeliac disease;

Autoantibodies;

Tissue transglutaminase;

Protein kinase $\mathrm{C}$ delta

\begin{abstract}
Post-translational modification of proteins by deamidation or transamidation by tissue transglutaminase (tTG) has been suggested as a possible mechanism for the development of autoimmunity. Sequence analysis of protein kinase $\mathrm{C}$ delta (PKC $\delta$ ) identified an amino acid motif that suggested the possibility that PKC $\delta$ was a glutamine substrate of tTG and MALDI-TOF analysis of synthesised peptides from PKC $\delta$ proved that this was the case. Polymerisation experiments using recombinant tTG and biotinylated hexapeptide substrate incorporation assays demonstrated that PKC $\delta$ is a substrate for tTG-mediated transamidation. Elevated levels of anti-PKC $\delta$ antibodies were detected in sera from patients with coeliac disease $(p<0.0001)$ but not from patients with other autoimmune disorders. These data suggest that a subset of patients with coeliac disease produce autoantibodies against PKC $\delta$ and that this response may stem from a tTG-PKC $\delta$ substrate interaction.

(c) 2013 Elsevier Inc. All rights reserved.
\end{abstract}

\section{Introduction}

Coeliac disease is characterised by an inappropriate immune response to storage proteins in certain cereal cultivars. These prolamin proteins cause intestinal inflammation which is associated with gastrointestinal complaints as well as nutritional deficiencies associated with reduced absorptive

\footnotetext{
* Corresponding author. Fax: + 35314024995.

E-mail address: greg.byrne@dit.ie (G. Byrne).
}

surface in the small intestine [1]. The disorder has a broad spectrum of severity with some individuals having asymptomatic disease, others having fulminant responses to ingestion of cereals such as wheat, barley and rye. The best-characterised and most immunogenic prolamins for coeliac patients are gliadin and glutenin derived from wheat gluten [2].

The immune response against prolamins results in the activation of cereal-specific $T$ cells that are of a Th1 cytokine profile and produce interferon gamma [3]. Inflammation in the small intestine leads to villous atrophy and 
crypt hyperplasia. Coeliac disease is also associated with humoral immune responses with antibodies produced against gluten and the autoantigen, tissue transglutaminase (tTG). The main reaction catalysed by tTG is the introduction of covalent $\varepsilon$-(c-glutaminyl)lysine cross-links between a glutamine donor protein and a lysine donor protein [4]. In the absence of a suitable lysine donor and in the presence of water, tTG can deamidate its target glutamine, giving rise to a glutamic acid residue. This enzyme plays an important role in the disease through the site-specific deamidation of glutamine residues in the prolamin peptides. The tTG-mediated deamidation results in negatively charged residues at important anchor positions for binding to HLA-DQ2, the coeliac disease-associated MHC class II molecule. The increased binding of gliadin peptides to $\mathrm{DQ} 2$ results in more potent $\mathrm{T}$ cell responses to gliadin peptides [5].

The mechanisms by which tTG becomes an autoantigen are not well understood but the hapten carrier complex model as proposed by Ludwig Sollid suggests that covalent attachment of gluten peptides to tTG facilitates their uptake by tTG-specific B cells which receive help from gluten-specific T cells. However, some research has demonstrated the presence of tTG-reactive T cells in patients with coeliac disease which could drive the autoantibody response [6]. The recent development of highly sensitive and specific neoepitope assays where the antigen is a complex of tTG and deamidated gliadin supports this notion that the gliadin-tTG interaction drives the initial autoimmune response in coeliac disease $[7,8]$. The detection of IgA class anti-tTG antibodies is a highly sensitive and specific marker of coeliac disease. Anti-tTG antibodies are detected by ELISA and the endomysial antibody (EMA) assay, which is an indirect immunofluorescence-based assay using monkey oesophagus. Other investigators have also reported the presence of further auto-antibodies in coeliac sera including antibodies to cytoskeletal actin filaments [9-11], to epithelial cells [12], desmin [13], calreticulin [14] and unidentified antigens [15,16]. Intriguingly, actin has been shown to act as a substrate of tTG [17], suggesting the possibility that a tTG-actin interaction leads to epitope spreading from tTG to actin. Smooth muscle autoantibodies (including those against actin) have been associated with the observation of an "atypical" endomysial pattern, obscuring the traditional fishnet pattern [18].
Protein kinase $\mathrm{C}$ delta $(\mathrm{PKC} \delta)$ is one of 9 isoforms of the protein kinase $\mathrm{C}$ enzyme family which are phospholipiddependant serine/threonine kinases that control a variety of cellular mechanisms including proliferation, differentiation and cell death [19]. Sequence analysis of PKC $\delta$ using the established algorithm [5] for tTG substrate identification identified a short span $\left({ }^{541} \mathrm{MLIGQSPFH}^{549}\right)$ within the catalytic domain of PKC $\delta$, which includes the consensus tTG glutamine substrate motif QXP where $X$ is any amino acid (Fig. 1).

In this study, we have investigated the possibility that PKC $\delta$ is a substrate for tTG and whether this enzyme-substrate interaction gives rise to a humoral anti-PKC $\delta$ response in patients with coeliac disease.

\section{Materials and methods}

\subsection{Deamidation/transamidation reactions}

The peptides MLIGQSPFH (from PKC $\delta$ ), ALPTAQVPTDP (from rat small heat shock protein 20) and PFPQPQLPYPR (from the DQ2- $\alpha$-I epitope from $\alpha$-gliadin) were synthesised in the Royal College of Surgeons in Ireland. The glutamine residues in bold represent the target for deamidation/transamidation by tTG.

Fifty micromolar concentrations of each peptide was incubated in reaction buffer $(100 \mathrm{mM}$ Tris- $\mathrm{HCl}, \mathrm{pH} 7.2)$ with $0.1 \mu \mathrm{g} / \mu \mathrm{l}$ of recombinant human $\mathrm{tTG}$, either in the presence (for transamidation) and absence (for deamidation) of $250 \mu \mathrm{M}$ of the primary amine 5-biotin-pentylamine (5BP). For deamidation analysis a direct comparison between the MALDI spectra acquired before and after transglutaminase reaction on the peptide mixture led to the identification of peptides containing glutamine $(\mathrm{Q})$ residues that were converted to glutamic acid $(\mathrm{E})$ residues by $\mathrm{tTG}$-mediated deamidation. Peaks originating from modified peptides showed a mass shift of $1 \mathrm{Da}$ for each modified $\mathrm{Q}$ residue. For analysis of transamidation incorporation of 5BP was observed as a mass increment of $311 \mathrm{Da}$ in the mass spectra. MALDI-ToF only shows whether transamidation has occurred or not, and does not give any quantitative result. The reaction was performed at $37^{\circ} \mathrm{C}$. Five $\mu \mathrm{l}$ aliquots were removed at given time-points and the reaction stopped by adding iodoacetamide to a final

Regulatory Domain

Catalytic Domain

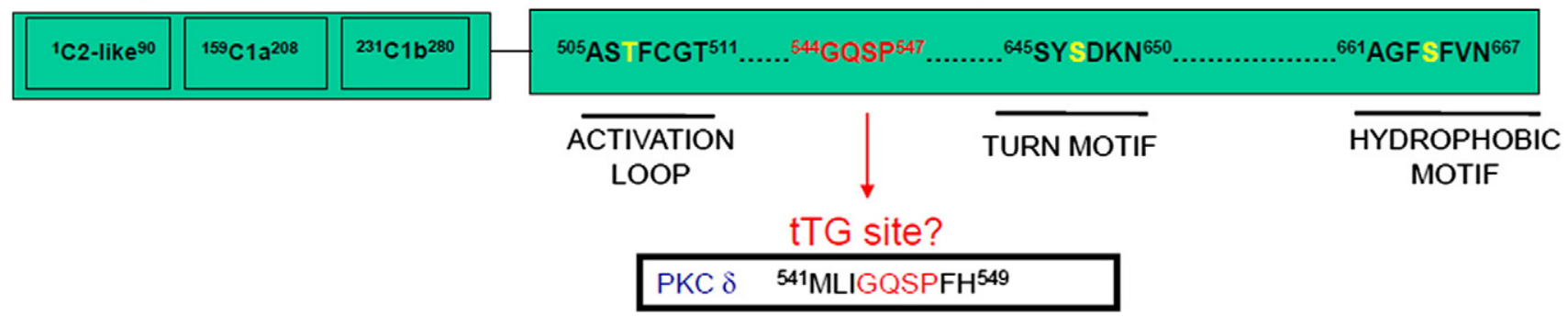

Figure 1. Potential tissue transglutaminase substrate consensus motif site on human PKC $\delta$. Located along the regulatory domain of PKC $\delta$ are the individual membrane binding domains, such as the C2-like and DAG/PMA binding motifs (C1a and C1b). Indicated on the catalytic domain of the enzyme are the positions of the phosphorylatable serine/threonine residues such as the activation loop domain (phosphorylatable amino acids are in yellow). Located C-terminal to the activation-loop threonine is a sequence (GQSP), which potentially represents a tTG consensus substrate sequence (GQXP motif where $\mathrm{x}=$ any amino acid). 
concentration of $5 \mathrm{mM}$. Aliquots were removed for analysis after 8, 16, 45 and 96 min.

\subsection{MALDI-ToF analysis}

The samples were diluted in $0.1 \%$ trifluoroacetic acid and spotted directly on a MALDI target plate ("dry-droplet") 1:1 with $5 \mathrm{mg} / \mathrm{ml} \alpha$-cyano-4-hydroxycinnamic acid as matrix. Each spectrum saved is the sum of approximately 1000 shots.

\subsection{Polymerisation assays}

One microgram of recombinant human PKC $\delta$ (Merck Biosciences) was incubated in the presence or absence of $1 \mu \mathrm{g}$ recombinant human tTG (Roboscreen) in a reaction buffer containing $100 \mathrm{mM}$ Tris, $10 \mathrm{mM} \mathrm{CaCl}_{2}, 10 \mathrm{mM} \mathrm{DTT}(\mathrm{pH} \mathrm{8)}$ for 30 min at $37^{\circ} \mathrm{C}$.

\subsection{Western blotting}

Samples were separated on a $12 \%$ SDS-PAGE gel, transferred to a PVDF membrane and probed for polymerisation products using a 1:1000 dilution of mouse anti-human tTG CUB7402 (Labvision) or a 1:1000 dilution of mouse anti-human PKC $\delta$ (Santa Cruz). Bands were detected by the addition of rabbit anti-mouse HRP (Dako) and developed with a solution containing $12 \mathrm{mls} 100 \mathrm{mM}$ Tris, $60 \mu \mathrm{l} 250 \mathrm{mM}$ luminol, $26.6 \mu \mathrm{l} 90 \mathrm{mM}$ p-coumaric acid and $3.8 \mu \mathrm{l} \mathrm{30 \%} \mathrm{H}_{2} \mathrm{O}_{2}$.

\subsection{Hexapeptide substrate incorporation assays}

Two N-terminally biotinylated hexapeptides, biotin-GQDPVR (Q-donor) and biotin-GNDPVK (K-donor), were used as probes to detect tTG-catalysed crosslinking. One microgram of recombinant human tTG (Roboscreen), $1 \mu \mathrm{g}$ recombinant PKC $\delta$ (Calbiochem) and $2.5 \mu \mathrm{g}$ of either lysine or glutamine substrate biotinylated hexapeptide probe were incubated in a reaction buffer containing $100 \mathrm{mM}$ Tris, $10 \mathrm{mM} \mathrm{CaCl} 2,10 \mathrm{mM}$ DTT ( $\mathrm{pH} \mathrm{8)}$ at $37{ }^{\circ} \mathrm{C}$ for $30 \mathrm{~min}$ (final volume $25 \mu \mathrm{l}$ ). In each assay a tube containing tTG, glutamine substrate probe and known tTG substrate N,N dimethylcasein (Sigma Aldrich) was included as a positive control. Reaction volumes were separated in a $12 \%$ SDS-PAGE gel and blotted onto a PVDF membrane. After blocking for $1 \mathrm{~h}$ with $5 \%$ non-fat dried milk with $0.1 \%$ Tween-20, blots were probed with Extravidin $®$ peroxidase (Sigma-Aldrich). Blots were developed for $3 \mathrm{~min}$ in a solution containing $12 \mathrm{mls} 100 \mathrm{mM}$ Tris, $60 \mu \mathrm{l} 250 \mathrm{mM}$ luminol, $26.6 \mu \mathrm{l} 90 \mathrm{mM}$ p-coumaric acid and $3.8 \mu \mathrm{l} \mathrm{30 \%} \mathrm{H}_{2} \mathrm{O}_{2}$.

\subsection{Serum samples}

Serum samples were collected from 30 patients with coeliac disease (11 male, 19 female; age 22-77, median 46). Diagnosis was based upon a positive endomysial antibody test as well as elevated anti-tTG antibody levels and positive duodenal biopsy results. Sera from 15 healthy controls ( 2 male, 13 female; age 20-56; median 28) were also analysed. Disease control samples included samples from 8 patients with systemic lupus erythematosis (1 male, 7 female; age 4-41; median 27) and 15 samples from patients with granulomatosis with polyangiitis (9 male, 4 female; range 12-80; median 57). Ethical approval for this study was obtained from the joint ethics committee of St James's and Tallaght hospitals.

\subsection{PKC $\delta$ ELISA assay}

ELISAs were performed by coating 96-well Maxisorp ${ }^{\circledR}$ plates (Nunc) with $1 \mu \mathrm{g}$ per well of recombinant human PKC $\delta$ (Sigma-Aldrich) overnight at $4{ }^{\circ} \mathrm{C}$. Wells were blocked with $1 \%$ HSA (Sigma-Aldrich) in PBS for $1 \mathrm{~h}$ and washed four times with PBS plus $0.1 \%$ Tween between each step. Human sera were diluted 1:20 with PBS plus $0.1 \%$ Tween followed by 1:1000 rabbit anti-human IgA conjugated to HRP (Dako). All antibody incubations were performed at room temperature for $1 \mathrm{~h}$. ELISAs were developed using 3,3',5,5'-tetramethylbenzidine liquid substrate system (Sigma-Aldrich) and were read at $450 \mathrm{~nm}$ in a spectrophotometer. A cut off for positivity was established as the mean +2 SD of the control population.

\subsection{Statistical analysis}

ELISA results from different sample groups were analysed using the non parametric Mann-Whitney $U$ test.

\section{Results}

\subsection{A peptide sequence from PKC $\delta$ is a substrate for deamidation by tTG}

Analysis of the amino acid sequence of PKC $\delta$ identified a glutamine-containing sequence (MLIGQSPFH) that, according to the algorithm determined by Vader et al., represented a potential glutamine substrate sequence for tTG (Fig. 1). The motif QXP where $X$ is any amino acid is reported to be a good substrate for tTG-mediated deamidation [5]. In order to test this hypothesis a peptide corresponding to the PKC $\delta$ sequence was synthesised and tested for deamidation by tTG using MALDI-ToF analysis. The known peptide substrates ALPTAQVPTDP from rat heat shock protein 20 and PFPQPQLPYPR from the DQ2- $\alpha$-I epitope from $\alpha$-gliadin were used as positive controls ( $Q$ residues in bold are known targets for deamidation by tTG). Deamidation can be calculated from the acquired MALDI-ToF mass spectra by calculating the centroid shift in the isotopic peak of the peptide. A complete shift of $1 \mathrm{Da}$ equals one complete deamidation.

Incubation of tTG with PKC $\delta$ peptide MLIGQSPFH resulted in a centroid shift in the isotopic peak that was visible at the 45-minute time point indicating deamidation had taken place. While deamidation occurred in the PKC $\delta$ peptide, it was considerably slower than the control peptides, which both demonstrated deamidation after 8 min (Figs. 2a \& b).

\subsection{A peptide sequence from PKC $\delta$ is a crosslinked to $5 \mathrm{BP}$ in vitro}

In order to determine whether the peptide MLIGQSPFH from PKC $\delta$ could act as a glutamine substrate for tTG in a transamidation reaction, the peptide was incubated in reaction buffer with tTG and 5BP, a well-characterised lysine substrate of tTG. Incorporation of 5BP into MLIGQSPFH 
a

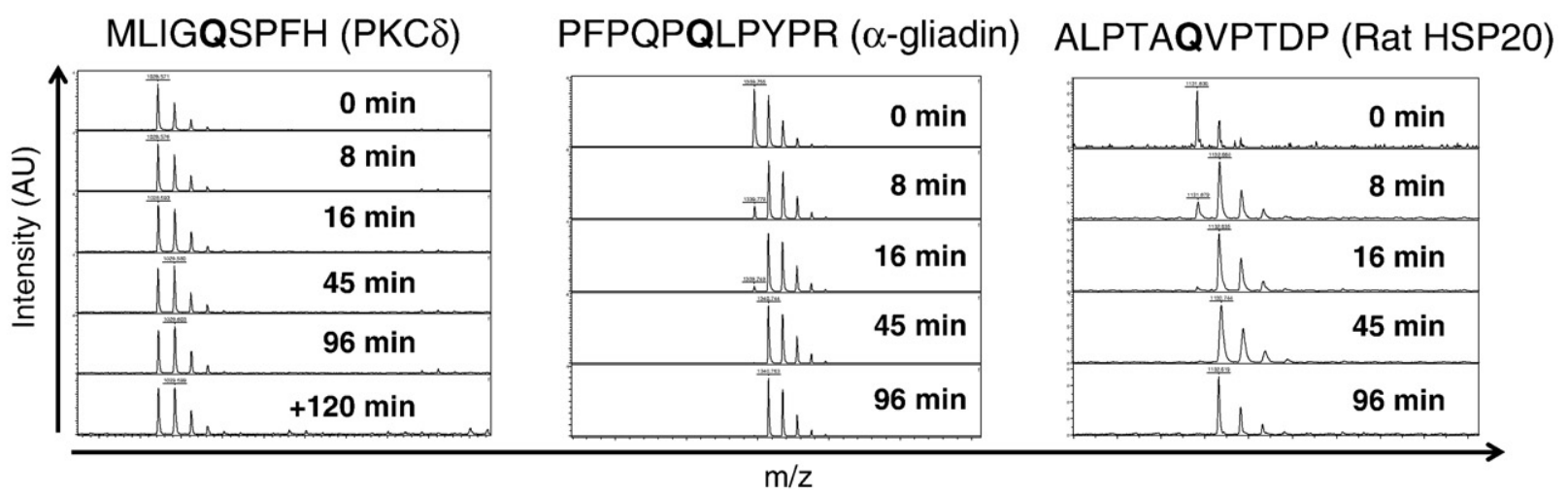

b

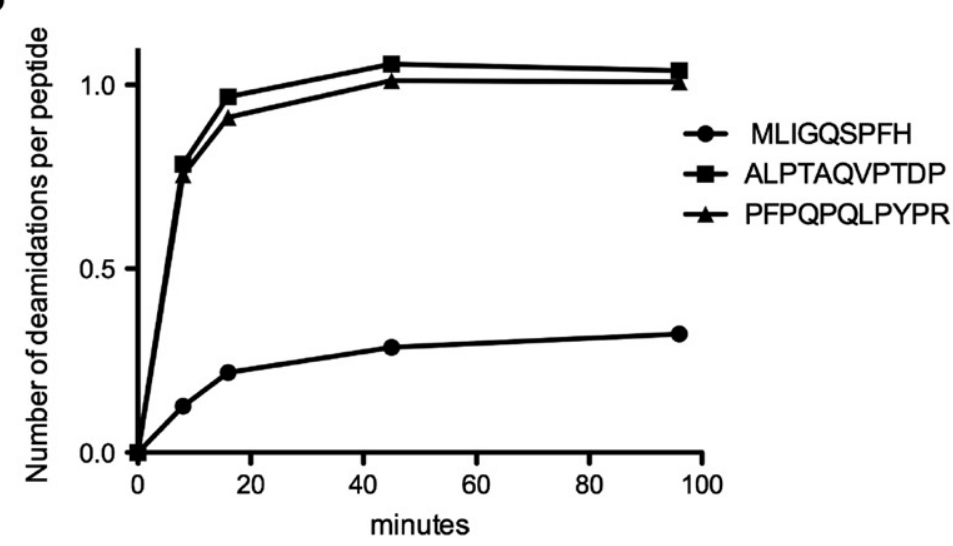

C

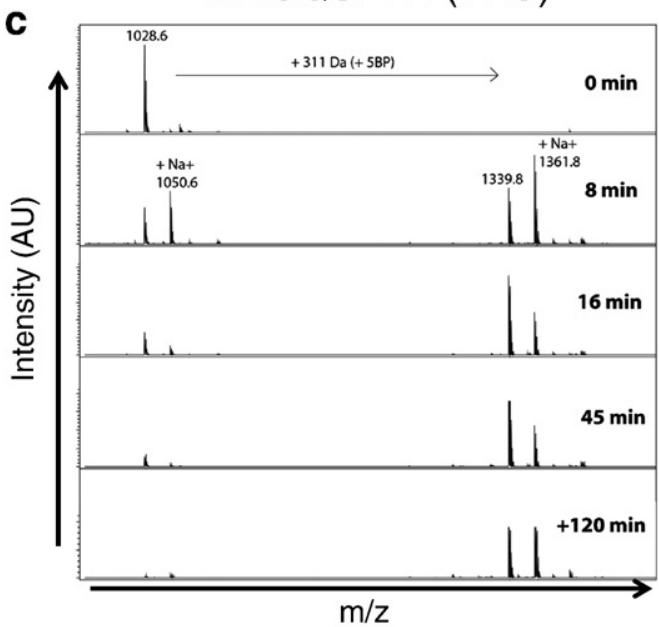

Figure 2. The peptide MLIGQSPFH derived from PKC $\delta$ is deamidated and transamidated by tTG. a: Deamidation of the glutamine residue in the peptide can de calculated from the acquired MALDI-TOF mass spectra by calculating the centroid shift in the isotopic peak of the peptide. A complete shift of $1 \mathrm{Da}$ equals one complete deamidation. Deamidation of MLIGQSPFH is less than that of known deamidation targets PFPQPQLPYPR from gliadin or ALPTAQVPTDP from rat small heat shock protein 20. b: Deamidation reactions represented as deamidations per peptide over $96 \mathrm{~min}$. c: Transamidation with 5BP is reflected by a mass increment of 311 Da in the mass spectra.

results in a $311 \mathrm{Da}$ increase in mass that can be detected by MALDI-ToF. Analysis of the transamidation reaction demonstrated an increase in mass corresponding to 5BP indicating that the PKC $\delta$-derived peptide is a substrate for tTG-catalysed transamidation (Fig. 2c).

\subsection{Recombinant PKC $\delta$ is a glutamine substrate of $t T G$}

The incorporation of biotinylated hexapeptide probes is an established method for the investigation of potential substrates of tTG [20]. Incorporation of lysine-containing probe (biotin-GNDPVK) indicates that a protein is a glutamine substrate of tTG, while the incorporation of glutaminecontaining probe (biotin-GQDPVR) indicates that a protein is a lysine substrate of tTG. In these experiments, the incorporation of the probes was investigated by using extravidin peroxidase to detect biotinylated proteins in Western blots. The known glutamine substrate $N^{\prime} N$-dimethylcasein was used as a positive control.

Blots showed the presence of a tTG-dependant band in reactions containing the lysine substrate probe and $\mathrm{PKC} \delta$ at the apparent molecular weight of tTG $(\sim 80 \mathrm{kDa})$. This result demonstrates that tTG can act as a lysine substrate for itself (Fig. 3). In the same lane, a biotinylated protein band was visible at high molecular weight, at the interface between stacking and resolving gels. No band was apparent at the molecular weight of recombinant PKC $\delta$ that was slightly lower at $77.5 \mathrm{kDa}$ suggesting that PKC $\delta$ does not behave as a lysine substrate for tTG. In the reactions containing the glutamine substrate probe, PKC $\delta$ and $\mathrm{tTG}$, a biotinylated band was visible at the molecular weight of $\mathrm{PKC} \delta$, indicating that it behaves as a glutamine substrate for tTG. Once again, a high molecular weight biotinylated band was apparent at the interface between stacking and resolving gels.

\section{4. tTG catalyses the formation of high molecular weight PKC $\delta$-tTG complexes}

A reaction mixture containing $\mathrm{PKC} \delta$ and tTG was incubated at $37{ }^{\circ} \mathrm{C}$ for 30 min and then subjected to Western blotting in order to characterise any resulting high molecular weight complexes. Western blots with a monoclonal anti-PKC $\delta$ 


\begin{tabular}{|lccccc|}
\hline & 1 & 2 & 3 & 4 & 5 \\
PKC & + & + & + & + & - \\
tTG & - & + & - & + & + \\
Biotin Q & + & + & - & - & - \\
Biotin K & - & - & + & + & + \\
DMC & - & - & - & - & + \\
\hline
\end{tabular}

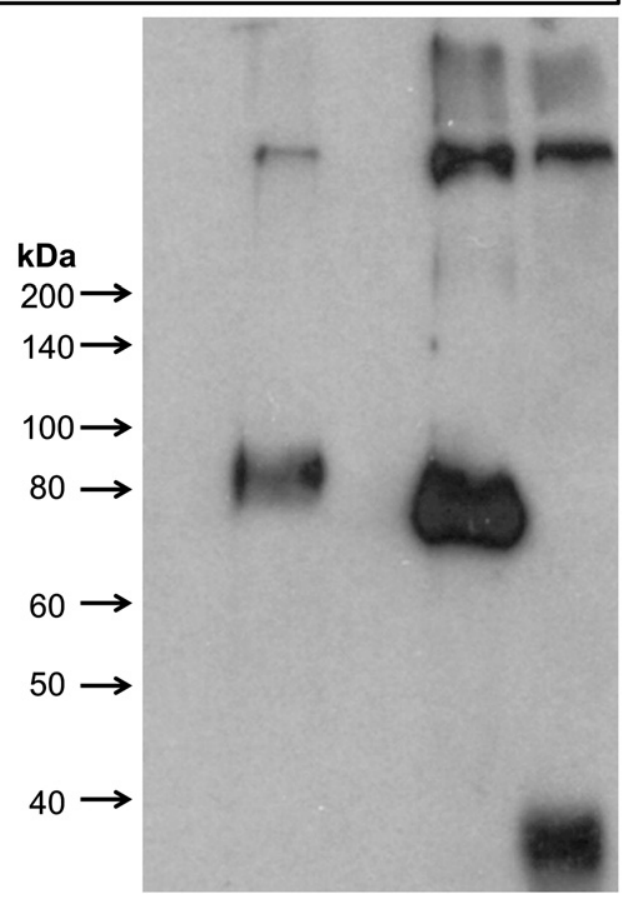

Figure 3. Western blot demonstrating the incorporation of hexapeptide substrate probes into PKC $\delta$ and tTG. Recombinant tTG and PKC $\delta$ were incubated in a transglutaminase reaction buffer with biotinylated hexapeptides that are established glutamine and lysine substrates for tTG. Western blots were probed with Extravidin $₫$ peroxidase in order to detect incorporated probes. In the absence of tTG (lanes $1+3$ ) no probes are incorporated into $\mathrm{PKC} \delta$. In lane 2 a band appears at the molecular weight of tTG as well as a high molecular weight band where the lysine substrate probe has been incorporated. In lane 4 a band appears at the molecular weight of PKC $\delta$ as well as a high molecular weight band where the glutamine substrate probe has been incorporated. Lane 5 contains DMC, a known glutamine substrate of tTG. The glutamine substrate probe has been incorporated into DMC resulting in a band at $30 \mathrm{kDa}$.

antibody showed that incubation with tTG resulted in a reduction of the PKC $\delta$ band intensity (Fig. 4a). A longer exposure time revealed higher molecular weight bands at $\sim 160 \mathrm{kDa}$ and at the stacking/resolving gel interface (Fig. 4b). Western blots of polymerisation reactions with a monoclonal anti-tTG antibody demonstrated that incubation of tTG and $\mathrm{PKC} \delta$ resulted in high molecular weight bands of equal size to those observed in the $\mathrm{PKC} \delta$ blots suggesting that the high molecular weight bands are tTG-PKC $\delta$ heterodimers (Fig. 4c). A band at the molecular weight of PKC $\delta$ was also apparent after the polymerisation reaction occurred. The reason for the
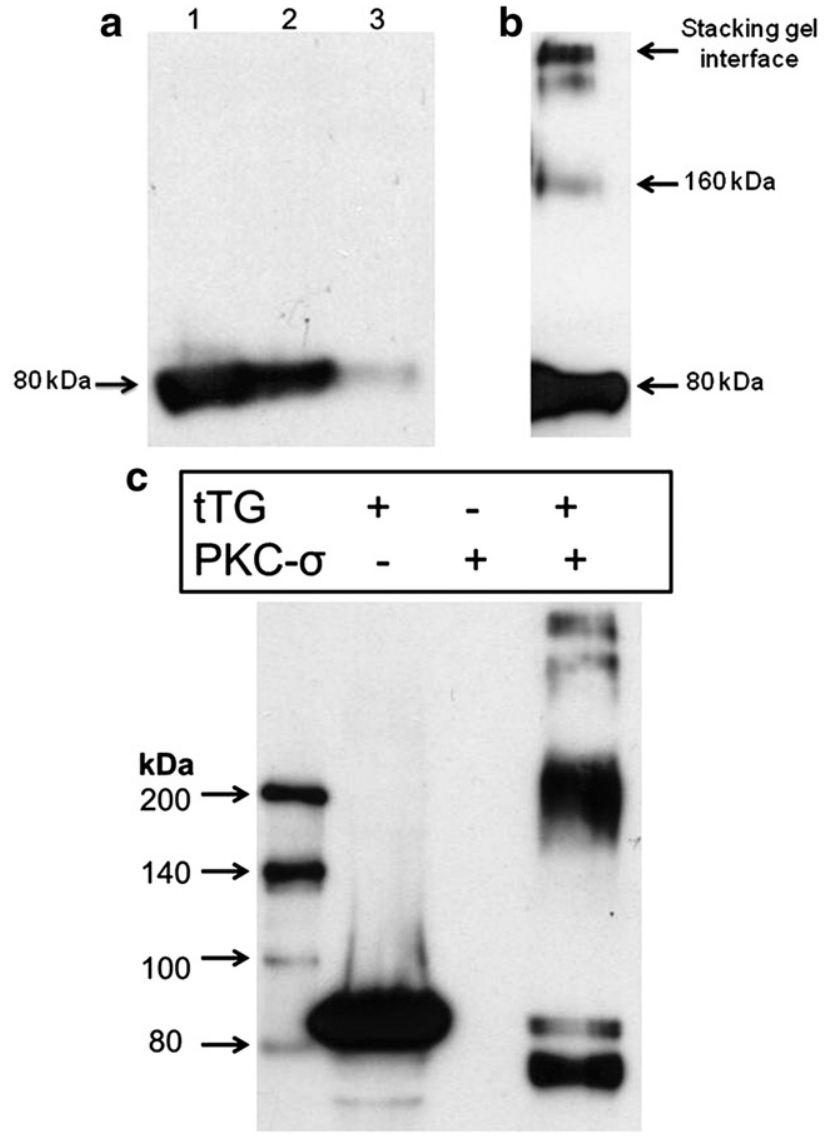

Figure 4. tTG catalyses the polymerisation of PKC $\delta$. a: The combination of PKC $\delta$ and $\mathrm{TTG}$ in a transglutaminase reaction buffer results in the reduction of the PKC $\delta$ band at $80 \mathrm{kDa}$ detected by Western blotting with anti-human PKC $\delta$. Lane 1: $1 \mu \mathrm{g}$ of recombinant PKC $\delta$. Lane 2: Mock polymerisation reaction $-1 \mu \mathrm{g}$ of PKC $\delta$ in reaction buffer with no tTG. Lane 3: The addition of tTG resulted in the reduction of the PKC $\delta$ band. b: A longer exposure of lane 3 from Fig. 3a reveals the presence of higher molecular weight bands at $\sim 160 \mathrm{kDa}$ and at the stacking/resolving gel interface. c: A polymerisation reaction containing $\mathrm{tTG}$ and $\mathrm{PKC} \delta$ results in the production of high molecular weight bands that are recognised by a monoclonal anti-tTG antibody in a Western blot. A band also becomes apparent at the molecular weight of PKC $\delta$.

appearance of this band is unknown but the deamidation of PKC $\delta$ by tTG could potentially result in the formation of a neoepitope that interacts with the anti-tTG monoclonal antibody.

\subsection{Elevated levels of IgA anti-PKC $\delta$ antibodies are detectable in sera from patients with coeliac disease but not in patients with other autoimmune conditions}

ELISAs were performed with sera from patients with coeliac disease, granulomatosis with polyangiitis, systemic lupus erythematosis and control samples using recombinant PKC $\delta$ as antigen. A highly significant $(\mathrm{p}<0.0001)$ increase in IgA anti-PKC $\delta$ was observed in the coeliac sera, but not in control sera or either autoimmune disease control (Fig. 5). There was no correlation between levels of anti-PKC $\delta$ 


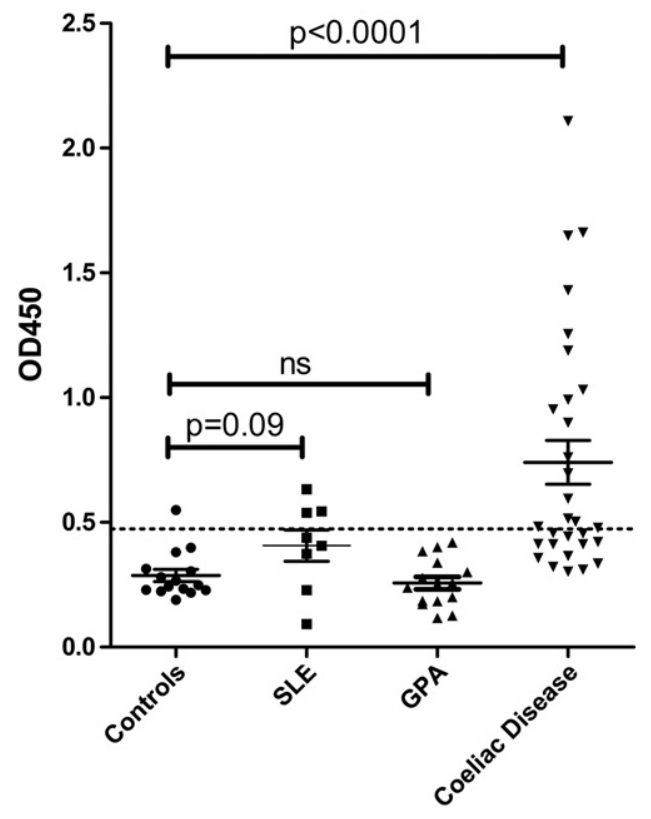

Figure 5. Patients with coeliac disease produce elevated levels of IgA anti-PKC $\delta$. Sera from patients with coeliac disease contain elevated levels of anti-PKC $\delta$ autoantibodies $(p<0.0001)$. Cut-off for positivity is represented by a dotted line and was calculated based on the mean +2SD of the results from the control samples. Disease controls were systemic lupus erythematosis (SLE) and granulomatosis with polyangiitis (GPA).

antibodies and anti-tTG antibodies $\left(R^{2}=0.09\right.$, data not shown). Of the coeliac disease patient sera, 17 of $30(57 \%)$ demonstrated elevated anti-PKC $\delta$ antibodies. Those samples with the highest levels of anti-PKC $\delta$ antibodies (OD>1.4) were reported as having an atypical EMA pattern that is associated with the production of other autoantibodies.

\section{Discussion}

In these experiments we have demonstrated that PKC $\delta$ is a glutamine substrate for tTG-mediated deamidation and transamidation. Amino acid sequence analysis identified a tTG substrate motif (QXP) in the catalytic domain of $\mathrm{PKC} \delta$ at position 545 and a peptide corresponding to the ${ }^{541}$ MLIGQSPFH $^{549}$ sequence of PKC $\delta$ was shown to be deamidated and transamidated by tTG in MALDI-ToF experiments. Biotinylated substrate probe incorporation assays and polymerisation assays were used to show that this enzyme-substrate interaction occurs in the full-length proteins and that tTG-PKC $\delta$ heterodimers are formed by the interaction. Finally, we have shown that a population of patients with coeliac disease has significantly elevated levels of IgA anti-PKC $\delta$ antibodies in their serum $(p<0.001)$ and that these autoantibodies are not elevated in patients with systemic lupus erythematosis or granulomatosis with polyangiitis.

tTG is a multifunctional enzyme which displays crosslinking, deamidation, ATPase and protein disulphide isomerase activity $[21,22]$. The enzyme has been implicated in cellular processes as diverse as apoptosis [23], tissue repair [24], G-protein signalling [25] and cytokine activation [26,27]. The enzyme plays a role in the modification of gluten peptides in coeliac disease and, through this interaction, becomes the target of an IgA autoantibody response. The widely held belief is that tTG-catalysed gliadin-tTG heterodimers act as a hapten-like complexes which drive the production of anti-tTG antibodies facilitated by gliadin-specific T-cell help [28]. While tTG is the primary autoantigen in coeliac disease, some patients have been shown to produce elevated levels of antibodies against other self proteins including actin, desmin, reticulin, liver, brain and parietal cell antigens [29]. tTG-mediated posttranslational modification of proteins by deamidation or transamidation is a possible mechanism for neoepitope generation and the development of autoimmunity. It is noteworthy that autoantigens (including actin, myosin and Histone $2 B$ ) from a variety of autoimmune diseases are substrates for tTG [30]. It is therefore conceivable that tTG-substrate interactions could result in epitope spreading to other autoantigens.

A number of proteins that are involved in the apoptotic process have been found to be autoantigens in disease states. The effective clearance of apoptotic cells is essential in the maintenance of tolerance and dysregulated phagocytosis of apoptotic cells has been implicated in the pathogenesis of SLE [31]. Significantly elevated levels of apoptosis have been observed in epithelial cells of the coeliac disease small intestine [32]. The main mechanism responsible for this phenomenon appears to be pro-inflammatory cytokine-induced increases in FAS/FASL expression [33]. PKC $\delta$ and TTG have both been described as having integral roles in the control of apoptosis $[23,34]$. Activation of tTG during apoptosis could result in significant modification of the antigenic profile of dying cells. Furthermore, crosslinking of proteins found in apoptotic blebs could increase the half-life of these proteins, thus increasing the exposure of these proteins to the immune system. It has been demonstrated that the induction of apoptosis in colon cancer cell lines is associated with shuttling of PKC $\delta$ to the cell membrane potentially making it available for tTG interaction and exposure to the immune system [35].

The production of anti-actin responses in coeliac disease has been associated with the atypical EMA pattern and more severe disease [11]. It is worth noting that in this study, PKC $\delta$ autoantibody levels tended to be higher in those patients that had an atypical EMA pattern (data not shown). Why some patients tend to produce antibody responses against other self-antigens is unknown but we propose a model whereby increased apoptosis in the coeliac small intestine results in the exposure of intracellular antigens on apoptotic cells which become available for tTG-mediated modification. This results in a longer protein half life or neoepitope formation, which culminates in autoantibody formation. Whether these autoantibodies play a role in coeliac disease pathogenesis is unknown but, given that $\mathrm{PKC} \delta$ is normally intracellular, they are unlikely to interact with their target molecule except in the context of apoptosis or necrosis.

PKC $\delta$ is a signalling molecule which plays roles in diverse cellular pathways including cell growth, proliferation, differentiation and death [19]. In pancreatic cells, it has been demonstrated that PKC $\delta$ regulates the expression of tTG and that inhibition or silencing of PKC $\delta$ results in decreased tTG expression and a concomitant increase in autophagy in these cells [36]. Consistent with the finding that PKC $\delta$ regulates tTG expression, is the fact that the 
phenotype of the tTG knockout mouse [37] and the PKC $\delta$ knockout mouse [38] is remarkably similar. Interestingly, both $\mathrm{tTG}^{-/-}$and $\mathrm{PKC}^{-/-}$mice contain circulating autoantibodies and display immune complex glomerulonephritis and splenomegaly.

The discovery that PKC $\delta$ is a substrate for tTG cross-linking suggests the possibility that tTG-mediated cross-linking could act as a regulator of PKC $\delta$ activity in a negative feedback loop. The majority of intracellular tTG is assumed inactive due to a scarcity of $\mathrm{Ca}^{2+}$ but recent evidence has confirmed that during the early stages of apoptosis perinuclear tTG assumes its active conformation and is capable of crosslinking proteins [39].

In summary we have demonstrated that PKC $\delta$ is a novel glutamine substrate for the enzyme tTG and that the tTG-PKC $\delta$ interaction results in heterodimer formation. Furthermore we have shown that a subset of patients with coeliac disease produce autoantibodies that bind $\mathrm{PKC} \delta$. The origin and significance of this response demand further investigation.

\section{Conflict of interest statement}

The author(s) declare that there are no conflicts of interest.

\section{Acknowledgments}

The authors wish to thank Dr. J.W. Drijfhout, Leiden for providing the biotinylated hexapeptide probes. Dr. Marc Devocelle of RCSI, Dublin carried out peptide synthesis. We would also like to extend our thanks to Dr. Jorunn Stamnæs from the Centre for Immune Regulation, Institute of Immunology, University of Oslo who carried out the MALDI-ToF experiments.

\section{References}

[1] K. Lindfors, M.L. Lahdeaho, S. Kalliokoski, K. Kurppa, P. Collin, M. Maki, K. Kaukinen, Future treatment strategies for celiac disease, Expert Opin. Ther. Targets 16 (2012) 665-675.

[2] F. Koning, Celiac disease: quantity matters, Semin. Immunopathol. 34 (2012) 541-549.

[3] S.W. Qiao, R. Iversen, M. Raki, L.M. Sollid, The adaptive immune response in celiac disease, Semin. Immunopathol. 34 (2012) 523-540.

[4] M. Griffin, R. Casadio, C.M. Bergamini, Transglutaminases: nature's biological glues, Biochem. J. 368 (2002) 377-396.

[5] L.W. Vader, A. de Ru, Y. van der Wal, Y.M. Kooy, W. Benckhuijsen, M.L. Mearin, J.W. Drijfhout, P. van Veelen, F. Koning, Specificity of tissue transglutaminase explains cereal toxicity in celiac disease, J. Exp. Med. 195 (2002) 643-649.

[6] R. Ciccocioppo, A. Finamore, E. Mengheri, D. Millimaggi, B. Esslinger, W. Dieterich, F. Papola, S. Colangeli, V. Tombolino, D. Schuppan, G.R. Corazza, Isolation and characterization of circulating tissue transglutaminase-specific $T$ cells in coeliac disease, Int. J. Immunopathol. Pharmacol. 23 (2010) 179-191.

[7] T. Matthias, S. Pfeiffer, C. Selmi, M. Eric Gershwin, Diagnostic challenges in celiac disease and the role of the tissue transglutaminase-neo-epitope, Clin. Rev. Allergy Immunol. 38 (2010) 298-301.

[8] S.D. Lytton, E. Antiga, S. Pfeiffer, T. Matthias, A. SzaflarskaPoplawska, V.K. Ulaganathan, W. Placek, P. Fabbri, R. Hall, M. Caproni, Neo-epitope tissue transglutaminase autoantibodies as a biomarker of the gluten sensitive skin disease - dermatitis herpetiformis, Clin. Chim. Acta 415 (Jan 16 2013) 346-349.
[9] M. Clemente, M. Musu, R. Troncone, C. Ciacci, T. Not, E. Neri, P. Strisciuglio, G. Maggiore, L. Cicotto, G. Sole, G. Gasbarrini, G. Corazza, U. Volta, A. Fasano, S. De Virgiliis, Detection of autoantibodies against enterocyte actin filaments as serological predictive test for intestinal villous atrophy in celiac disease: results of a polycentric study, Gastroenterology 124 (2003) A660.

[10] M.G. Clemente, M.P. Musu, R. Troncone, U. Volta, M. Congia, C. Ciacci, E. Neri, T. Not, G. Maggiore, P. Strisciuglio, G.R. Corazza, G. Gasbarrini, L. Cicotto, G. Sole, A. Fasano, S. De Virgiliis, Enterocyte actin autoantibody detection: a new diagnostic tool in celiac disease diagnosis: results of a multicenter study, Am. J. Gastroenterol. 99 (2004) 1551-1556.

[11] A. Granito, P. Muratori, F. Cassani, G. Pappas, L. Muratori, D. Agostinelli, L. Veronesi, R. Bortolotti, N. Petrolini, F.B. Bianchi, U. Volta, Anti-actin IgA antibodies in severe coeliac disease, Clin. Exp. Immunol. 137 (2004) 386-392.

[12] A.M. Teppo, C.P. Maury, Enzyme immunoassay of antibodies to epithelial glycoprotein: increased level of antibodies in coeliac disease, J. Immunol. Methods 74 (1984) 327-336.

[13] K. Teesalu, O. Uibo, N. Kalkkinen, P. Janmey, R. Uibo, Increased levels of IgA antibodies against desmin in children with coeliac disease, Int. Arch. Allergy Immunol. 126 (2001) 157-166.

[14] L. Tuckova, K. Karska, J.R. Walters, M. Michalak, P. Rossmann, S. Krupickova, E.F. Verdu, R. Saalman, L.A. Hanson, H. Tlaskalova-Hogenova, Anti-gliadin antibodies in patients with celiac disease cross-react with enterocytes and human calreticulin, Clin. Immunol. Immunopathol. 85 (1997) 289-296.

[15] I.R. Korponay-Szabo, K. Laurila, Z. Szondy, T. Halttunen, Z. Szalai, I. Dahlbom, I. Rantala, J.B. Kovacs, L. Fesus, M. Maki, Missing endomysial and reticulin binding of coeliac antibodies in transglutaminase 2 knockout tissues, Gut 52 (2003) 199-204.

[16] H.H. Uhlig, J. Lichtenfeld, A.A. Osman, T. Richter, T. Mothes, Evidence for existence of coeliac disease autoantigens apart from tissue transglutaminase, Eur. J. Gastroenterol. Hepatol. 12 (2000) 1017-1020.

[17] Z. Nemes Jr., R. Adany, M. Balazs, P. Boross, L. Fesus, Identification of cytoplasmic actin as an abundant glutaminyl substrate for tissue transglutaminase in HL-60 and U937 cells undergoing apoptosis, J. Biol. Chem. 272 (1997) 20577-20583.

[18] D. Lasagni, R. Ferrari, M. Lapini, Unmasking anti-endomysial antibodies in coeliac subjects positive for anti-smooth muscle antibodies, Acta Paediatr. 88 (1999) 462-464.

[19] M. Freeley, D. Kelleher, A. Long, Regulation of protein kinase C function by phosphorylation on conserved and non-conserved sites, Cell. Signal. 23 (2011) 753-762.

[20] S. Boros, B. Kamps, L. Wunderink, W. de Bruijn, W.W. de Jong, W.C. Boelens, Transglutaminase catalyzes differential crosslinking of small heat shock proteins and amyloid-beta, FEBS Lett. 576 (2004) 57-62.

[21] L. Fesus, M. Piacentini, Transglutaminase 2: an enigmatic enzyme with diverse functions, Trends Biochem. Sci. 27 (2002) 534-539.

[22] G. Hasegawa, M. Suwa, Y. Ichikawa, T. Ohtsuka, S. Kumagai, M. Kikuchi, Y. Sato, Y. Saito, A novel function of tissue-type transglutaminase: protein disulphide isomerase, Biochem. J. 373 (2003) 793-803.

[23] L. Fesus, Z. Szondy, Transglutaminase 2 in the balance of cell death and survival, FEBS Lett. 579 (2005) 3297-3302.

[24] E.A. Verderio, T.S. Johnson, M. Griffin, Transglutaminases in wound healing and inflammation, Prog. Exp. Tumor Res. 38 (2005) 89-114.

[25] Z. Sarang, P. Molnar, T. Nemeth, S. Gomba, T. Kardon, G. Melino, S. Cotecchia, L. Fesus, Z. Szondy, Tissue transglutaminase (TG2) acting as $\mathrm{G}$ protein protects hepatocytes against Fas-mediated cell death in mice, Hepatology 42 (2005) 578-587.

[26] D.L. Cecil, R. Terkeltaub, Transamidation by transglutaminase 2 transforms S100A11 calgranulin into a procatabolic cytokine for chondrocytes, J. Immunol. 180 (2008) 8378-8385. 
ARTICLE IN PRESS

8

G. Byrne et al.

[27] L. Huang, J.L. Haylor, M. Fisher, Z. Hau, A.M. El Nahas, M. Griffin, T.S. Johnson, Do changes in transglutaminase activity alter latent transforming growth factor beta activation in experimental diabetic nephropathy? Nephrol. Dial. Transplant. 25 (2010) 3897-3910.

[28] L.M. Sollid, O. Molberg, S. McAdam, K.E. Lundin, Autoantibodies in coeliac disease: tissue transglutaminase - guilt by association? Gut 41 (1997) 851-852.

[29] R. Shaoul, A. Lerner, Associated autoantibodies in celiac disease, Autoimmun. Rev. 6 (2007) 559-565.

[30] M. Piacentini, V. Colizzi, Tissue transglutaminase: apoptosis versus autoimmunity, Immunol. Today 20 (1999) 130-134.

[31] W.H. Shao, P.L. Cohen, Disturbances of apoptotic cell clearance in systemic lupus erythematosus, Arthritis Res. Ther. 13 (2011) 202.

[32] S.F. Moss, L. Attia, J.V. Scholes, J.R. Walters, P.R. Holt, Increased small intestinal apoptosis in coeliac disease, Gut 39 (1996) 811-817.

[33] R. Ciccocioppo, A. Di Sabatino, R. Parroni, P. Muzi, S. D'Alo, T. Ventura, M.A. Pistoia, M.G. Cifone, G.R. Corazza, Increased enterocyte apoptosis and Fas-Fas ligand system in celiac disease, Am. J. Clin. Pathol. 115 (2001) 494-503.

[34] M.E. Reyland, Protein kinase Cdelta and apoptosis, Biochem. Soc. Trans. 35 (2007) 1001-1004.
[35] S.G. Weller, I.K. Klein, R.C. Penington, W.E. Karnes Jr., Distinct protein kinase $\mathrm{C}$ isozymes signal mitogenesis and apoptosis in human colon cancer cells, Gastroenterology 117 (1999) 848-857.

[36] B. Ozpolat, U. Akar, K. Mehta, G. Lopez-Berestein, PKC delta and tissue transglutaminase are novel inhibitors of autophagy in pancreatic cancer cells, Autophagy 3 (2007) 480-483.

[37] Z. Szondy, Z. Sarang, P. Molnar, T. Nemeth, M. Piacentini, P.G. Mastroberardino, L. Falasca, D. Aeschlimann, J. Kovacs, I. Kiss, E. Szegezdi, G. Lakos, E. Rajnavolgyi, P.J. Birckbichler, G. Melino, L. Fesus, Transglutaminase 2-/- mice reveal a phagocytosis-associated crosstalk between macrophages and apoptotic cells, Proc. Natl. Acad. Sci. U. S. A. 100 (2003) $7812-7817$.

[38] A. Miyamoto, K. Nakayama, H. Imaki, S. Hirose, Y. Jiang, M. Abe, T. Tsukiyama, H. Nagahama, S. Ohno, S. Hatakeyama, K.I. Nakayama, Increased proliferation of B cells and auto-immunity in mice lacking protein kinase Cdelta, Nature 416 (2002) 865-869.

[39] M.S. Pavlyukov, N.V. Antipova, M.V. Balashova, M.I. Shakhparonov, Detection of transglutaminase 2 conformational changes in living cell, Biochem. Biophys. Res. Commun. 421 (2012) 773-779.

Please cite this article as: $\mathrm{G}$. Byrne, et al., Protein kinase $\mathrm{C}$ delta is a substrate of tissue transglutaminase and a novel autoantigen in coeliac disease, Clin. Immunol. (2013), http://dx.doi.org/10.1016/j.clim.2013.01.007 